\title{
ATTITUDE OF RURAL COMMUNITY TOWARDS HEALTH CARE UTILIZATION AT PRIMARY LEVEL PUBLIC HEALTH FACILITIES
}

\author{
MD. ZIAUL ISLAM ${ }^{1}$, SANJOY KUMAR CHOWDHURY ${ }^{2}$, SHARMIN FARJANA ${ }^{3}$
}

\begin{abstract}
:
Objective: The study was conducted to assess the attitude of rural community towards health care utilization at primary level public health facilities.

Study Design: Descriptive cross sectional study carried out over a period of six months from June to November 2007.
\end{abstract}

Study Setting: A randomly selected village (Lohagach) of Sreepur Upazila under Gazipur district.

Subjects: 305 randomly selected adult (age 15-60 years) household members who are permanent residents of the said area.

Materials and methods: Data was collected by face to face interview with a semi-structured questionnaire.

Results: Among the 305 respondents, $55.40 \%$ are male and $44.60 \%$ are female with mean age of 32.39 years ( $\pm S D$ 11.94). Most respondents have educational qualification up to secondary level $(32.10 \%)$ while some up to primary level (21\%). Majority of the respondents are housewives (35.40\%) and Service holders (20.30\%) having an average monthly family income of TK. 7805.57 ( \pm SD 6442.24).

It is evident from the study that; females, respondents from older age group, and those from higher monthly family income has less appreciation for existing primary level public health facilities. Also, the higher the education level of the respondent, the lower was the level of satisfaction regarding healthcare received at primary level public health facilities.

As regards to availability of healthcare; insufficiency of doctors (52.8\%) \& prescribed medicine supply (75.4\%) and lack of appropriate and necessary laboratory investigation (64.6\%) \& surgical treatment facilities (62.6\%) are identified by the respondents as major setbacks.

The study reveals key impediments pointed out by the respondents which interfere with their easy access to quality healthcare at these facilities; including long waiting time (60.3\%), insufficient waiting room facilities (64.9\%) and inadequate duration of consultation with physician (50.2\%). Major constraints associated with primary health care utilization are mostly due to lack of awareness (22.66\%) and transportation problem (22.6\%).

Key words: Attitude of Rural Community, Health Care Utilization, Primary Level Public Health Facilities

\section{Introduction:}

Universal Declaration of Human Rights declares the right of every individual to a standard of living adequate for the health and well-being of himself and of his family. 1,2 Yet ironically; 'health' till date remains, literally, a long-sought-after 'wealth' to developing countries like ours. In Bangladesh, the mainstream of healthcare is its public sector. The government provides health care services to the larger segment of the country, the rural community, through primary level public health facilities, which comprise Upazila Health Complex, Union Sub-Center, Union

1. Assistant Professor, Department of Community Medicine, National Institute of Preventive and Social Medicine (NIPSOM), Mohakhali, Dhaka

2. MBBS Student (Batch K-61), Dhaka Medical College, Dhaka

3. MBBS Student (Batch K-60), Dhaka Medical College, Dhaka 
Family Welfare Center \& Community Clinic. ${ }^{3}$ But it is observed that the existing health care facilities at the primary level are underutilized or poorly utilized. Different constraints are underpinning this unexpected utilization of health care service at primary level within public sector; among which are irrational allocation of health resources, lack of coordination with other sectors, lack of trained health personnel \& quality service, lack of infrastructure \& logistics, lack of awareness of consumers, superstitions, illiteracy, lack of accessibility \& affordability. All these constraints ultimately influence the attitudes of the consumers or the patients towards utilization of health care facilities at any level.

\section{Rationale:}

It is evident that equitable \& efficient distribution of healthcare services can improve the health status of a community. Majority of our population reside in the rural areas \& health status varies significantly \& systematically between rural-urban locations. So, on this basis of reality, it is now imperative to unveil the attitude of rural community towards healthcare utilization at primary level public health facilities.

The Government of Bangladesh (GOB) spends a significant fraction of its healthcare budget for the rural people, in terms of investment in primary level public health facilities. In an endeavor to find out the real scenario, the attitude of those rural communities who are the target of this extensive health service delivery network towards the tangible utilization of healthcare facilities provided in these primary level public health facilities is what this study considers with utmost importance.

Attitude towards healthcare utilization is regarded as a complex function developed from the interplay of the services demanded by the consumers and those provided by the providers. This specific study assesses the attitude of rural community considering both. Along with these, the study also considers accessibility to health services in times of need, affordability, affability and quality of care provided by primary level public health facilities.

The findings of this research, therefore, is intensely valuable not only for health planning and policy making to reform the health sector, but also in adequately pointing out the means by which attitudes of rural community can be changed and their health seeking behavior can be shifted to ideal ones. This research also makes recommendations for improving accessibility, affordability and quality of services provided at the primary level health care facilities which will play a vital role in improving the quality of life of rural communities. Moreover, this pertinent study is a source of courage and inspiration for conducting relevant studies in larger scales in future.

\section{Materials and Methods:}

This was a Descriptive cross-sectional study. The study was conducted in a randomly selected village (Lohagach) of Sreepur upazila under Gazipur district during the period of 6 (six) months (from June 2007 to November 2007). We have register the entire adult (15-60 years aged) permanent residents of the study place who are physically and psychologically sound and giving informed consent. 305 cases were found statistically significant. Simple random sampling technique were used during data collection. A semistructured questionnaire were finalized after pretesting and used to collect relevant information from the respondents. Then data were collected by face-toface interview. It was processed by editing \& postcoding as required. Data were analyzed by computer with the help of SPSS software (version 15.0).

\section{Results:}

This study revealed the following socio-demographic characteristics of the respondents:

Socio-demographic (Major) Findings

variable

\begin{tabular}{ll}
\hline Sex & Male: $55.40 \% ;$ Female: $44.60 \%$ \\
Age & Mean 32.39 years ( \pm SD 11.94) \\
Marital Status & Married : 73.80\%; \\
& Unmarried : $22 \%$; Widow : 4.30\% \\
Religion & Muslim : $97 \% ;$ Hindu : $3 \%$ \\
Educational & Secondary level : $32.10 \% ;$ \\
qualification & Primary level : $21 \% ;$ \\
& Illiterate : $16.10 \%$ \\
Occupation & Housewife : $35.40 \% ;$ \\
& Service holders : $20.30 \% ;$ \\
& Businessman : $19.70 \%$
\end{tabular}

Monthly family $\quad$ TK.7805.57 ( \pm SD 6442.24$)$

income

Family Size $\quad 4.78( \pm$ SD 2.06$)$

When it comes to choosing a healthcare provider, $52.1 \%$ preferred private practitioners (MBBS doctors) while preferences of $46.9 \%$ respondents were in favor of Upazila Health Center (Fig.-1). The reason behind this was that primarily, $57 \%$ respondents appreciated 
effective treatment followed by $39 \%$ preferring health center due to close proximity to their residence. Some inclination by $20.7 \%$ was shown in support of cheap treatment while some other $13.5 \%$ were in favor of free treatment. $27.5 \%$ preferences were in favor of getting prescription or medicine. So it can be concluded that effective treatment is preferred to any length of distance that hinders the procurement of heath facilities.

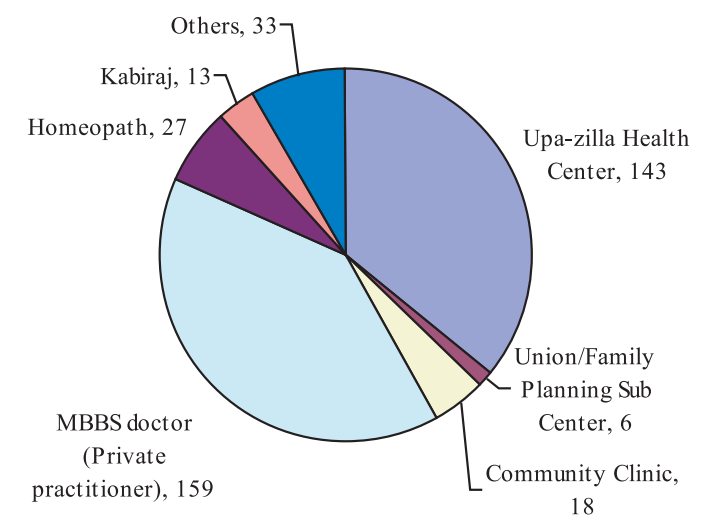

$\square$ Upa-zilla Health Center $\square$ Community Clinic

$\square$ Homeopath

$\square$ Others

Fig.-1: Health care centers preferred by respondents

In our interview about distance of the health center, the majority (53.5\%) did not agree to the statement that the health center is far away from their residence. Regarding accessibility to health care, majority (51.5\%) commented that they had easy access to health care at the health center.

When asked about insufficiency of doctors, majority $(52.8 \%)$ opined that the number of doctors available in the health care centre is not sufficient. Only $18.2 \%$ people said that all prescribed drugs are available in the health center whereas $75.4 \%$ people believed the opposite. $64.6 \%$ respondents agreed with the statement that appropriate and necessary laboratory investigation facilities were unavailable.

The attitude of rural community towards the quality of service they receive at primary level public health facilities was also assessed. $60.3 \%$ respondents complained that they had to wait for a long time in the healthcare center before their desired consultation with the doctor. Although 57.7\% respondents were happy about the co-operation of the health personnel, $50.2 \%$ gave opinion that the duration of consultation is not adequate. A staggering $64.9 \%$ alleged that there were insufficient waiting room facilities. $62.6 \%$ people agreed that surgical treatment facilities are inadequate in the health centers.

According to the study, only $1.5 \%$ of the respondents complained about poor availability of the healthcare services, all of them were female. Interestingly, it found out that, the higher the education level of the respondent, the lower the level of satisfaction regarding healthcare received at primary level public health facilities (Table 1). The respondents from TK.2000-5000 \& TK.5001-10000 were mostly satisfied about the availability and quality of healthcare received from these centers. All these findings were statistically significant $(p<0.05)$ (Table II \& III)..

The study unveiled that major constrains associated with utilization of healthcare at primary level public health facilities are mostly due to lack of awareness (22.66\%) and transportation problem (22.6\%). Next constraint is the unavailability of public health care center (18.5\%). Financial problem (14.4\%) also plays an important role here. There are some other factors which include lack of education (7.1\%), superstition $(2.6 \%)$, religious barrier $(2.6 \%)$ and social norms and restrictions $(0.9 \%)$. These findings correlate with the real picture of our country.

Table-I

Attitude of rural community towards availability of health care by education

\begin{tabular}{|c|c|c|c|c|c|c|c|c|}
\hline \multirow{2}{*}{$\begin{array}{l}\text { Level of } \\
\text { Education }\end{array}$} & \multicolumn{4}{|c|}{ Attitude of rural community } & \multirow{2}{*}{$\begin{array}{c}\text { Total } \\
(\%)\end{array}$} & \multicolumn{3}{|c|}{$\mathrm{X}^{2}$ test } \\
\hline & Excellent (\%) & Good (\%) & Fair (\%) & Poor $(\%)$ & & $\mathrm{X}^{2}$ value & $\mathrm{df}$ & pvalue \\
\hline Primary & 2.3 & 12.1 & 5.6 & 1.0 & 21.0 & 22.49 & 21 & 0.03 \\
\hline Secondary & 7.2 & 16.7 & 8.2 & 00 & 32.1 & & & \\
\hline $\mathrm{SSC}$ & 1.6 & 8.9 & 3.9 & 00 & 14.4 & & & \\
\hline HSC & 1.3 & 4.9 & 1.0 & 00 & 7.2 & & & \\
\hline Graduate & 0.7 & 3.3 & 0.3 & 0.3 & 4.6 & & & \\
\hline Master & 0.3 & 0.7 & 0.7 & 00 & 1.6 & & & \\
\hline Illiterate & 2.6 & 7.2 & 5.9 & 0.3 & 16.1 & & & \\
\hline Others & 0.7 & 1.3 & 1.0 & 00 & 3.0 & & & \\
\hline Total & 16.7 & 55.1 & 26.6 & 1.6 & 100 & & & \\
\hline
\end{tabular}


Table-II

Attitude of rural community towards availability of health care by monthly family income

\begin{tabular}{|c|c|c|c|c|c|c|c|c|}
\hline Monthly & \multicolumn{4}{|c|}{ Attitude of rural community } & \multirow{2}{*}{$\begin{array}{c}\text { Total } \\
(\%)\end{array}$} & \multicolumn{3}{|c|}{$\mathrm{X}^{2}$ test } \\
\hline Income & Excellent(\%) & Good(\%) & Fair(\%) & Poor $(\%)$ & & $\overline{X^{2} \text { value }}$ & $\mathrm{df}$ & $P$ value \\
\hline$<2000$ & 0.3 & 1.3 & 1.3 & 00 & 3.0 & 5.94 & 12 & 0.04 \\
\hline $2000-5000$ & 7.5 & 23.6 & 11.5 & 0.7 & 43.3 & & & \\
\hline $5001-10000$ & 6.9 & 20.7 & 7.9 & 0.7 & 36.1 & & & \\
\hline $10001-20000$ & 1.6 & 8.2 & 4.6 & 0.3 & 14.8 & & & \\
\hline$>20000$ & 0.3 & 1.3 & 1.3 & 00 & 3.0 & & & \\
\hline Total & 16.7 & 55.1 & 26.6 & 1.6 & 100 & & & \\
\hline
\end{tabular}

Table-III

Attitude of rural community towards quality of health care by monthly income categories

\begin{tabular}{|c|c|c|c|c|c|c|c|c|}
\hline Monthly & \multicolumn{4}{|c|}{ Attitude of rural community } & \multirow{2}{*}{$\begin{array}{c}\text { Total } \\
(\%)\end{array}$} & \multicolumn{3}{|c|}{$\mathrm{X}^{2}$ test } \\
\hline Income & Excellent(\%) & Good $(\%)$ & Fair(\%) & Poor $(\%)$ & & $\mathrm{X}^{2}$ Value & $\mathrm{df}$ & PValue \\
\hline$<2000$ & 0.3 & 2.0 & 0.7 & 00 & 3.0 & 8.59 & 12 & 0.04 \\
\hline $2000-5000$ & 4.6 & 27.2 & 11.1 & 0.3 & 43.3 & & & \\
\hline $5001-10000$ & 6.6 & 19.0 & 9.2 & 1.3 & 36.1 & & & \\
\hline $10001-20000$ & 2.6 & 8.5 & 3.6 & 00 & 14.8 & & & \\
\hline$>20000$ & 0.3 & 2.0 & 0.7 & 0.0 & 3.0 & & & \\
\hline Total & 14.4 & 58.7 & 25.2 & 1.6 & 100 & & & \\
\hline
\end{tabular}

\section{Discussion:}

The study was carried out among 305 household members of Sreepur Upazila under Gazipur district to assess their attitude towards utilization of primary level health care facilities. The socio-demographic characteristics revealed by the study shows slight variation from the national statistics because Bangladesh Bureau of Statistics (BBS) obtains data from countrywide survey while our study obtained it from a specific rural community in a short period of time.

We learned from the study that, people of rural community prefer private practitioners $(\mathrm{PP})$ over public health facilities; as according to the respondents, the care provided by them is more effective. The availability and accessibility of PPs are also high in comparison to other health care providers. A minor bulk of population seeks health care from kabiraj or homeopath because they are not aware of modern treatment facilities. It was also found out that effective treatment is preferred to any length of distance that hinders the procurement of heath facilities.
A study conducted on primary health care services showed that Bangladesh has an extensive rural health care infrastructure, yet only $8 \%$ of the rural population is able to access the amenities of health care ${ }^{3,4} \mathrm{But}$ majority of the respondents in our study said that they get proper access to health care, which reveals that some health centers are providing good-quality facilities.

Insufficiency of doctors at the primary level public health facilities is one of the key complaints made by the respondents. A similar study conducted on health care system of Bangladesh revealed that the highest number of problems (22\%) in the health sector is related to inadequate number of physicians. ${ }^{1} \mathrm{As}$ a result people are losing interest in having treatment in the government health center and using nongovernment and other private hospitals for this purpose.

Unavailability of prescribed drugs is another disappointing scenario prevailing at these facilities. A similar study conducted by UBINIG in 1989 on illness behavior sponsored by Essential Drug Project, 
Bangladesh also mentioned that in Govt. health centers people were often disappointed regarding the availability of drugs. ${ }^{5}$ Another study conducted at Kaliganj UHC ${ }^{6-9}$ revealed that only $11.67 \%$ of the respondent got all prescribed medicine at hospital dispensary. Our study also gives almost same conjecture. The reasons behind the findings could be the lack of sincerity of staff along with scarcity of drug supply.

Another finding was the unavailability of appropriate and necessary laboratory investigation facilities, resultantly driving patients to private facilities. A similar study by Islam $\mathrm{K}$ was performed to compare the laboratory investigation facilities between rural and urban areas of Bangladesh revealed that among 18 recommended tests (i.e. urine for sugar, urine for albumin urine microscopic examination etc.) only 9 tests are provided by the rural health center. ${ }^{5,10-12}$ Our study reinforces the fact the laboratory services provided at the primary level public health facilities are not adequate for the people of rural Bangladesh.

While evaluating the quality of healthcare received at primary level public health facilities; the first predicament identified was the long waiting time. A similar study performed in rural Bangladesh on "Client satisfaction and quality of health care in rural Bangladesh" reveals that the average waiting time with which clients would be satisfied was 10-11 min. ${ }^{6}$, 13-16 About one third (28.2\%) of all users were not satisfied with the time they waited to receive care. Moreover, patients presenting for maternal care were significantly more dissatisfied $(37.6 \%)$ than clients presenting for other types of services. From our study it is clear that majority of the people are not satisfied due to this long waiting time. To make things worse, $64.9 \%$ respondents found waiting room facilities to be inadequate. A similar study that was performed regarding "Use of Upazila and Union-level Government Facilities"1, 17-19 showed that one-third (33\%) of the upazila health complexes did not have a separate room in the outpatient area for waiting. While most (88\%) Upazila health complexes had toilets in the outpatient area, only two-thirds (63\%) of these included a separate toilet for women. Of the 225 union health and family welfare center facilities visited, half had a separate waiting room. Where treatment facilities are merely adequate, the waiting room facilities has become nothing but a farce.
Almost all patients expect respect and politeness from the health personnel, and our stuffy received positive expression from the respondents about the co-operation of the health personnel. But, unfortunately, the duration of consultation with the doctor was not satisfactory for the most.

Another setback identified by the study was inadequate surgical facilities. A similar study that was performed in an upazila of Bangladesh reveals that the surgical facilities are poor in the upazila health complex ${ }^{19-21}$ and majority of the patients are not satisfied with this. This coincides with our study. Resource allocation and skilled technical hands are not so much available in rural Bangladesh and there is also lack in planning and management. As a result this dissatisfaction is increasing day by day.

Among the important statistically significant findings, first was that the response among males regarding availability of health services at primary level public health facilities is more positive than females. Similar results were found in another study where it was depicted that male utilization rates for both in-patient and outpatient services far exceed those of females. ${ }^{22}$, ${ }^{23}$ Our socio-economic structure acts as an influencing factor in this variation. In our country, women are comparatively less out-going \& less educated which have a great influence in narrowing their perception about different aspects of health \& health care facilities. So their response towards the availability of health care services is less than their counterpart.

The study highlights that highest availability of health care at primary level health facilities is seen among less educated respondents. It is also obvious from the result findings that there is a gradual decline in receiving primary level public health care facilities with the increase in educational status. A possible inference that can be drawn from this is that, increase in educational status creates demands for better quality of service, more compassion and accountability from health care providers.

The respondents from TK.2000-5000 \& TK.5001-10000 monthly family income were mostly satisfied about the availability and quality of healthcare received from these centers. This may be due to the fact that these people can't afford to pay for healthcare due to their financial constraints, and hence has to remain satisfied with whatever service they get by paying only for the ticket at OPD of primary level health centers. On the contrary, families from higher income 
group can enjoy the luxury of other options (eg. private practitioners) where they receive more care; which consequently increase their demand for quality care. Also, they are more aware of their right to information and clarification. However, not all the respondents from low-income group are fully satisfied, suggesting that people from all income groups are starting to demand more in this era of rising awareness about health.

\section{Conclusion:}

The findings extracted from study reflect that the attitude of most of the rural people towards health care utilization at primary level public health facilities was not encouraging; especially in respect of availability of healthcare, doctors, drugs, laboratory investigation and surgical treatment. Accessibility of the rural community to public health facilities was constrained by long waiting time, insufficient waiting room facilities and inadequate duration of consultation with physician, which was triggered by lack of awareness and transportation problem. These findings recommend immediate attention of health policy makers to take relevant strategies to ensure accessibility and utilization of primary level public health facilities by rural communities.

\section{References:}

1. Ministry of Health and Family Welfare, Government of Peoples Republic of Bangladesh. Management Information System (MIS), Directorate General of Health Services. Dhaka, Bangladesh, 2007.

2. K. Park. In: Park's Textbook of Preventive and Social Medicine. $19^{\text {th }}$ Edition. Jabalpur : Banarsidas Bhanot Publishers, India 2007: 2-244.

3. Rashid KM, Khabir M, Hyder S. In: Text book of community medicine and public health. $3^{\text {rd }}$ edition. Dhaka: RKH publishers, 1999: 27-34.

4. Haq, Naimul, Innovative approaches to healthcare and family planning services. 2001:4.

5. Hannan MA, Chowdhury MZ, Azad AK, Haque MM, Karim MR, Ahmed BN et al. Quality of services provided to the tuberculosis treated in a selected TB treatment centre. JOPSOM 2000; 19(1): 18-20.

6. Muslemuddin M. A comprehensive study on assessment of patient's care of out patient department between an intensified and nonintensified primary health care Upa-zilla Health Complex. Dhaka (Dissertation). NIPSOM, 1996: 31-57.
7. Bangladesh Bureau of Statistics. Statistical Yearbook of Bangladesh 2004. Dhaka 2004: 27-49.

8. Gazi R, Goodburn L, Chowdhury AMR, Karim F. Barriers to emergency obstetric care in a rural setting of Bangladesh. ICDDR, B, 1992-1993.

9. Reza M, Larson CP. Families of Migrant workers: patterns of health services utilization and coverage. ICDDR, B \& Mc Gill University, 2001-2003.

10. Prenger K, Williams S. Linking cultural beliefs in Bhut/Jinn with health care-seeking behavior. LAMB project, Parbatipur, Dinajpur and Monash University, 2001-2003.

11. Thurstone LL. A Law of comparative judgment. Psychological Review 1927; 34: 273-286

12. Thurstone LL. Attitudes can be measured. American Journal of Sociology 1928; 33: 529-54.

13. Luft HS, John C, Hershey JC, Morrell J. Factors affecting the use of physician services in a rural community. 1976; 66: 865-868.

14. Andersen R, Newman JE. "Social and individual determinants of medical care utilization in the United States". Milbank Memorial fund quarterly 1973; 51(1): 95-124.

15. Andersen RM, Davidson PL. "Measuring access and trends" in changing the US Health care system 1996.

16. Aday LA, Andersen R. "A framework for the study of access to medical care". Health service research 1974; 9: 208-20.

17. Phillips KA, Morrison KR, Andersen R, Aday LA. Understanding the context of health utilization: assessing environmental and provider related variables in the behavioral model of utilization. Health services research 1996; 33: 573-577.

18. Mirowsky J, Ross CE. "Patient satisfaction and visiting the doctor: A self regulatory system". Social science and medicine 1983; 17: 1353-61.

19. Maksuda AKM. Barriers in accessibility in basic health service facilities of rural poor. Health care practices of rural poor 2001; 1: 33-39.

20. Fosu GB. Access to health care in rural areas of developing societies. J Hlth soc Behav 1989; 30: 398-411.

21. Young JT, Menken J, Williams J, Khan N, Kuhn RS. Who Receives Healthcare? Age and Sex Differentials in Adult Use of Healthcare Services in Rural Bangladesh, 2005-2007. Bangladesh 2007: 17.

22. Aldana JM, Piechulek H, Al-Sabir A. Client satisfaction and quality of health care in rural Bangladesh. Bangladesh 1993: 5.

23. Khanun P. Service delivery at the union health and family welfare centers: the client's perspective, ICDDR, B, 1994. 